E3S Web of Conferences 1, 03008 (2013)

DOI: $10.1051 / \mathrm{e} 3$ sconf $/ 20130103008$

(C) Owned by the authors, published by EDP Sciences, 2013

\title{
Applications of a Turf Surrogate Surface Sampling Technique in Measuring Mercury Dry Deposition in Florida, USA
}

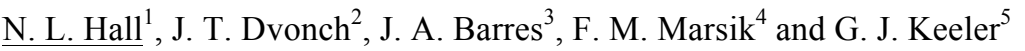 \\ ${ }^{1}$ University of Michigan Air Quality Laboratory, Ann Arbor, MI 48109, USA, hallnai@umich.edu \\ ${ }^{2}$ University of Michigan Air Quality Laboratory, Ann Arbor, MI 48109, USA, dvonch@umich.edu \\ ${ }^{3}$ University of Michigan Air Quality Laboratory, Ann Arbor, MI 48109, USA, jbarres@umich.edu \\ ${ }^{4}$ University of Michigan Air Quality Laboratory, Ann Arbor, MI 48109, USA, marsik@umich.edu \\ ${ }^{5}$ University of Michigan Air Quality Laboratory, Ann Arbor, MI 48109, USA, deceased.
}

\begin{abstract}
Atmospheric deposition of mercury $(\mathrm{Hg})$ is a major process that contributes mercury loadings in ecosystems resulting in the bioaccumulation of mercury in fish and other wildlife that has prompted public health concerns. Although methods for measuring mercury that is wet deposited have been well studied, there are limited established methods for directly measuring dry deposition of atmospheric mercury. A new method using a turf surrogate surface (TSS) technique was developed to address limitations in published dry deposition collection methods. This method was deployed on a large scale for the first time during measurement intensives conducted as part of a Hg Total Maximum Daily Load (TMDL) project in Florida, USA. Wet and dry deposition of mercury were measured at 15 sites in Florida in 2009 and 11 sites in 2010. The dry deposition of mercury measured during the month-long intensives ranged from $0.6 \mu \mathrm{g} / \mathrm{m}^{2}$ to $2.1 \mu \mathrm{g} / \mathrm{m}^{2}$. Wet deposition of mercury measured during the month-long intensives ranged from $1.5 \mu \mathrm{g} / \mathrm{m}^{2}$ to $6.9 \mu \mathrm{g} / \mathrm{m}^{2}$. A North- South spatial gradient was observed for wet deposition of mercury; however, dry deposition of mercury displayed more general variability.
\end{abstract}

Key Words: Mercury, wet deposition, dry deposition, turf surrogate surface, Florida, TMDL

\section{Introduction}

Atmospheric deposition is a process affecting concentrations of various pollutants in the ecosystem and is a crucial part of mercury's biogeochemical cycle. Mercury which can be deposited to water and land surfaces through wet and dry deposition processes is methylated in waterbodies and bioaccumulates in the foodweb resulting in high methylmercury levels in fish as well as other wildlife (Atkeson et al., 2002; Landis and Keeler, 2002). Elevated methylmercury concentration in fish is a public health concern impacting recreational fishers, subsistence fish-eaters as well as susceptible populations like pregnant women and young children (Rothenberg et al., 2008).

As a part of a mercury total maximum daily load (TMDL) project, the University of Michigan Air Quality Laboratory (UMAQL) established several short-term satellite sites positioned around existing multi-year project supersites in order to investigate the spatial patterns and variability of wet and dry deposition of mercury throughout four regions of Florida. The wet and dry deposition of major ionic species and a suite of trace elements were also collected to support source-receptor models and the determination of deposition processes. The intensives were conducted during summer months to take advantage of known high seasonal rainfall. Sites were chosen in rural, urban, industrial and coastal locations. Four to six additional sites were located around each of the project supersites. These sites added to the spatial coverage of wet deposition measurements that were on-going and added a turf surrogate surface (TSS) sampler to measure the dry deposition of mercury.

The TSS sampler method was developed to address some limitations of water surrogate surfaces (WSS) sampling including rainfall contamination and sample loss due to wind and evaporation. This was the first major field campaign where the TSS samplers were deployed across a large network of sites for dry deposition measurements. TSS sampling is particularly well suited for a climate like Florida where during summer there are frequent precipitation events. 


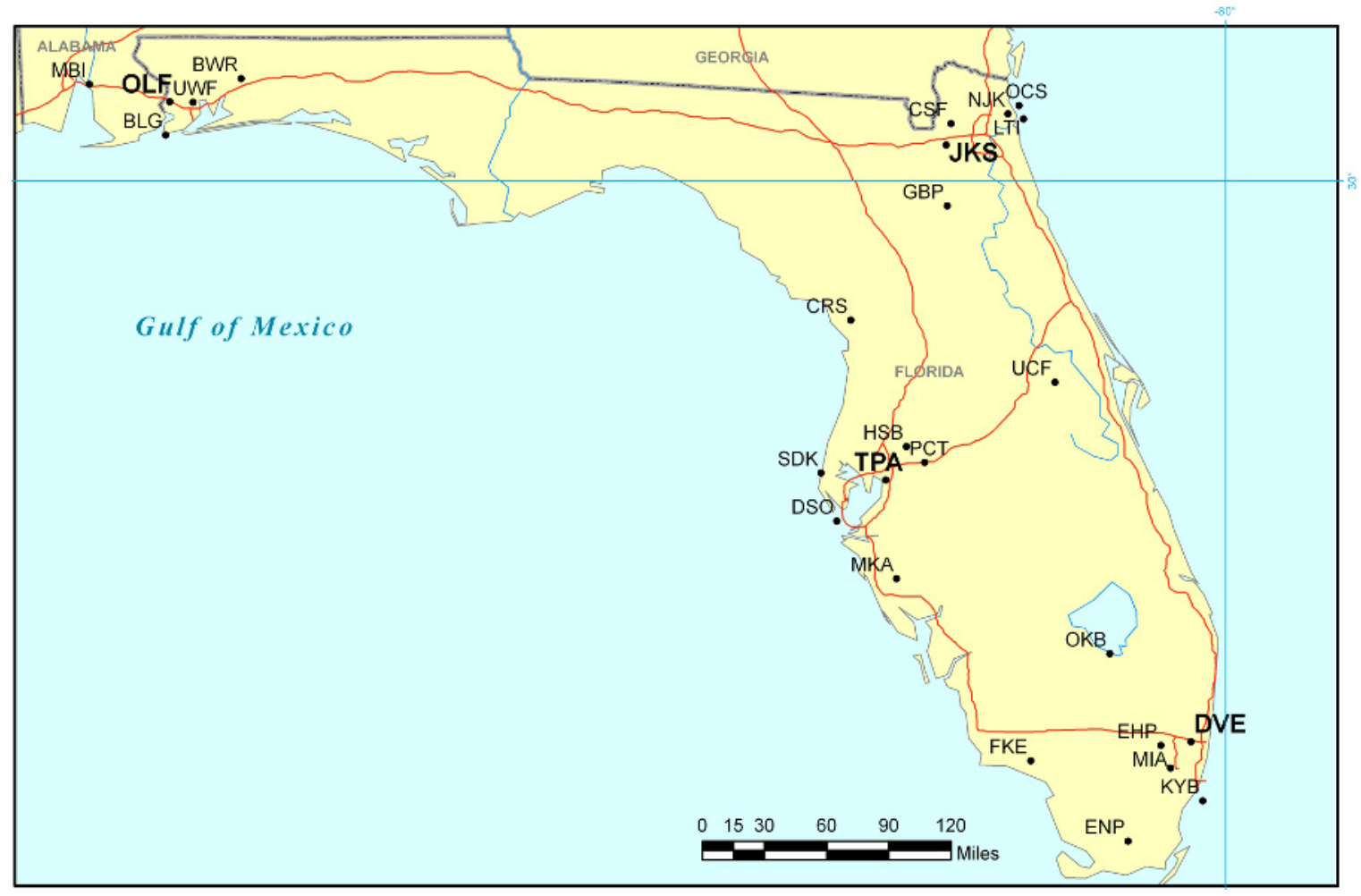

Fig. 1. Measurement intensive site locations in Florida, USA.

\section{Materials and Methods}

The measurement intensive satellite sites in Florida are shown in

Fig. 1. The Tampa measurement intensive was conducted from July 4-August 4, 2009. Seven sites (CRS, UCF, HSB, PCT, SDK, DSO, and MKA were located around the Tampa supersite (TPA; lat. 27.9137, long. 82.3749). The Davie measurement intensive was also conducted during July 4- August 4, 2009 and included the sites of OKB, FKE, EHP, MIA, KYB, and ENP located around the Davie supersite (DVE; lat. 26.0854, long. 80.2407). The Jacksonville measurement intensive was conducted between July 24- August 23, 2010 and included the sites of OCS, LTI, NJK, CSF, and GBP around the Jacksonville supersite (JKS; lat. 30.2475, long. -81.9516). The Pensacola measurement intensive was conducted between July 24- August 23, 2010 and included the sites of UWF, BLG, BWR, and MBI located around the Pensacola supersite (OLF; lat. 30.5500, long. 87.3751).

Dry deposition of mercury was measured using TSS methods. The TSS sampler shown in Figure 2 consists of a grass-like turf surface (approximately 1" high polyethylene blades) placed in a shallow Teflon well embedded in an aerodynamic airfoil. A bottle located beneath the Teflon well was connected via tubing and a vapor trap to capture a throughfall sample consisting of precipitation that occurred during the sampling period potentially enhanced with any deposition that washed off of and through the turf surface. Mercury was extracted from the turf surface through sonication and oxidation. The mass of mercury dry deposited was determined by summing the amount of mercury extracted from the turf with the amount of mercury in the throughfall sample, then subtracting the amount of mercury measured in precipitation samples collected in parallel with the TSS sampler. Turf surfaces were deployed for 72 hour periods. Throughfall samples were collected the morning following each precipitation event. Collocated turf samplers were deployed at DVE, TPA and JKS as part of a continuing effort to further evaluate the method. The dry deposition of major ions and trace elements were collected using similar methods in different sampling streams.

Daily precipitation samples were collected the morning following an event to measure wet deposition of mercury, trace elements and ions using manually deployed funnels and two different sampling trains using methods previously described (Dvonch et al., 1998; Landis and Keeler, 1997; White et al., 2009).Samples were analyzed for mercury, a suite of trace elements and major ions.

Sample analysis for wet and dry deposition samples was conducted at UMAQL. Mercury samples were oxidized to $1 \%$ solution (v/v) using concentrated $\mathrm{BrCl}$ and stored in a dark cold room until being analyzed for total mercury by cold vapor atomic fluorescence spectroscopy (CVAFS) using a Tekran Instruments Corporation (Knoxville, TN) Series 2600 Automated Water Analysis System following EPA Method 1631. Trace element samples were acidified with concentrated $\mathrm{HNO}_{3}$ to a $1 \%$ solution $(\mathrm{v} / \mathrm{v})$. Analysis was conducted on a Thermo Finnigan Element2 high-resolution magnetic sector field inductively coupled plasma mass 


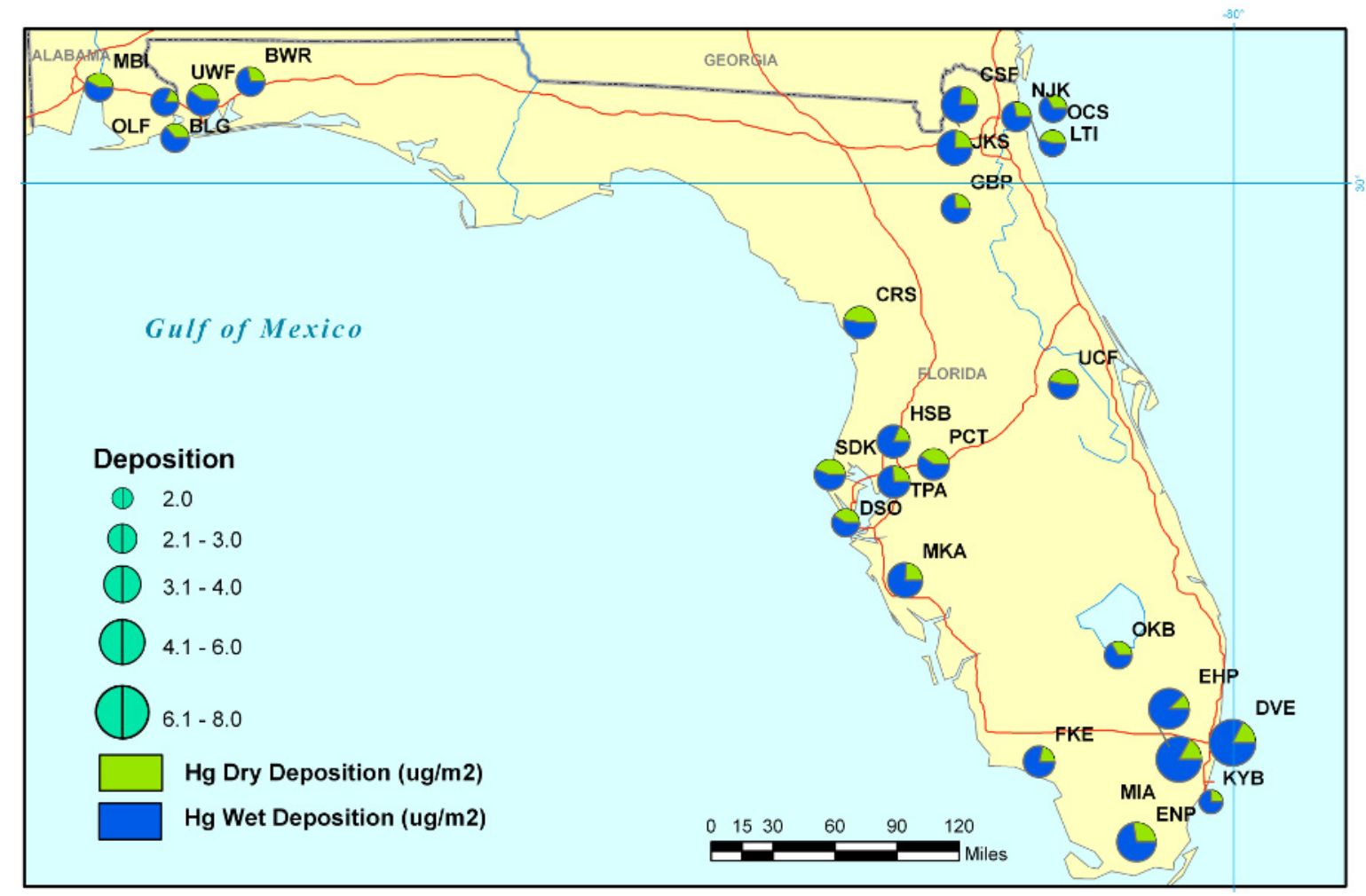

Fig. 3. Wet and dry deposition of $\mathrm{Hg}$ in Florida.

spectrometer (HR-ICPMS). Laboratory analysis for major ions was conducted using a Dionex (Sunnyvale, CA) ion chromatography system.

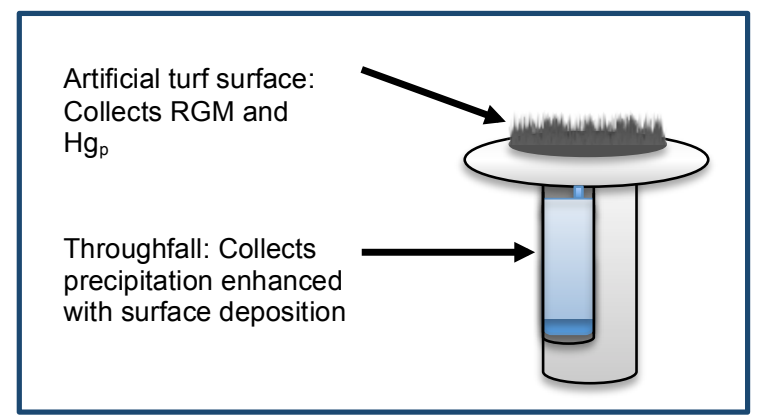

Fig. 2. Schematic of turf surrogate surface (TSS) sampler.

\section{Results and Discussion}

The total deposition of mercury measured during the month-long intensives varied widely ranging from 2.2-8.3 $\mu \mathrm{g} / \mathrm{m}^{2}$ at KYB (Davie intensive) and DVE (Davie intensive) respectively (see Figure 0 ). The dry deposition component ranged from $0.6 \mu \mathrm{g} / \mathrm{m}^{2}$ at OLF (Pensacola intensive) to $2.1 \mu \mathrm{g} / \mathrm{m}^{2}$ at CRS (Tampa intensive). The wet deposition component ranged from $1.5 \mu \mathrm{g} / \mathrm{m}^{2}$ at LTI (Jacksonville intensive) to $6.9 \mu \mathrm{g} / \mathrm{m}^{2}$ at DVE (Davie intensive, industrial area).

A North-South increasing gradient was observed for the total deposition of mercury in the state of Florida during the summer intensives. This North-South gradient was driven by a greater concentration of mercury in precipitation events and not by the precipitation amount which was the highest in the Pensacola intensive area (west). There were no large spatial trends observed for mercury dry deposition, although proximity to local emissions sources seems to be associated with higher mercury dry deposition.

The ratio of wet deposition to dry deposition of mercury was also highly variable across the sites in the study ranging from 1.1 at CRS to 5.8 at EHP. The wet to dry deposition ratios did not follow the same trends as wet or dry deposition, suggesting different mechanisms and factors influencing wet and dry deposition of mercury.

\section{Conclusion}

The turf surrogate surface sampling method has allowed widespread and in-depth study of the dry deposition of mercury in the state of Florida. It has enabled a unique comparison of wet to dry deposition methods at sites at a variety of locales in Florida and demonstrates that the ratio of wet to dry deposition of mercury is highly variable, and not simply driven by precipitation amounts or other easily estimated parameters. This turf surrogate surface method has been subsequently further utilized for a deposition study in Illinois during summer 2011 to evaluate local source contributions.

Further analyses will be conducted integrating statewide mercury emission sources, meteorology and ambient mercury concentrations with this wet and dry deposition dataset to investigate the factors influencing enhanced dry deposition of mercury and the factors driving the ratio of wet to dry deposition of mercury. 


\section{Acknowledgements}

Funding for this project was provided by the State of Florida Department of Environmental Protection. We thank Jane Clifford, Deborah Edelman, Summer Hitchens, Tiffany Jackson, Jason Demers, Sonia Mathew, Tyler Osburn, Laura Sherman, Emily Thomas, Dave Torrone, Emily White, Brandon Wills, Alex Costakis, Tim Finch, James Green, and Matt Salvadori for tremendous support in preparation and sample collection during the study. We also thank Mary Lynam, Masako Morishita and Nora Reyes for help with sample analysis and interpretation of data. This work is dedicated to the memory of Jerry Keeler who was crucial to the development of the TSS method and the design of this study.

\section{References}

Atkeson T, Axelrad D, Pollman C, Keeler G. Integrating Atmophseric Mercury Deposition and Aquatic Cycling in the Florida Everglades: An approach for conducting a Total Maximum Daily Load Analysis for an atmospherically derived pollutant. Florida Department of Environmental Protection, 2002.
Dvonch JT, Graney JR, Marsik FJ, Keeler GJ, Stevens RK. An investigation of source receptor relationships for mercury in south Florida using event precipitation data. Science of The Total Environment 1998; 213: 95-108.

Landis MS, Keeler GJ. Critical Evaluation of a Modified Automatic Wet-Only Precipitation Collector for Mercury and Trace Element Determinations. Environmental science \& technology 1997; 31: 2610-2615.

Landis MS, Keeler GJ. Atmospheric mercury deposition to Lake Michigan during the Lake Michigan Mass Balance Study. Environmental Science \& Technology 2002; 36: 4518-4524.

Rothenberg SE, Ambrose R, Jay J. Evaluating the potential efficacy of mercury total maximum daily loads on aqueous methylmercury levels in four coastal watersheds. Environmental science \& technology 2008; 42: 5400-5406.

White EM, Keeler G, Landis M. Spatial Variability of Mercury Wet Deposition in Eastern Ohio: Summertime Meteorological Case Study Analysis of Local Source Influences. Environmental science \& technology 2009; 43: 4946-4953. 